\title{
Hybrid Control Using Adaptive Fuzzy Sliding Mode Control of Doubly Fed Induction Generator for Wind Energy Conversion System
}

\author{
Djamila Cherifi*, Yahia Miloud ${ }^{1}$ \\ 1 GACA Laboratory, Department of Electrical Engineering, Faculty of Technology, Dr. Tahar Moulay University of Saida, \\ 20000 Ennasr, Saida, P. O. B. 138, Algeria \\ *Corresponding author, e-mail: d_cherifi@yahoo.fr
}

Received: 31 December 2019, Accepted: 17 March 2020, Published online: 21 September 2020

\begin{abstract}
In this paper, we are interested in the development of a robust control of active and reactive power for a Doubly Fed Induction Generator for variable speed wind energy using hybrid control by Adaptive Fuzzy logic and Sliding Mode Controller (AFSMC). This type of control is introduced to avoid the major disadvantage of variable structures systems which is the chattering phenomenon. Using the variable structure is to ensure the high dynamic of convergence and the robustness towards parametric variations and disturbances. Whereas the fuzzy control is introduced here in order to remove residual vibrations in high frequencies. Simulation results show that the proposed control strategy gives better results.
\end{abstract}

\section{Keywords}

Doubly Fed Induction Generator (DFIG), wind power generation systems, Adaptive Fuzzy logic and Sliding Mode Controller (AFSMC), hybrid control

\section{Introduction}

The use of wind energy conversion systems has developed into one of the most important new alternatives to conventional fossil fuels in recent years. It offers an excellent opportunity to generate electricity and contribute to respect for the environment $[1,2]$.

Doubly Fed Induction Generator (DFIG) is one of the most popular variable speed wind turbines in use nowadays because of its high performance in terms of systematic low cost, high energy efficiency, operating over a wide range of speed variation and extracting the maximum amount of power available. The complexity of its control was mainly due to the strong nonlinearity as a multiple-input multiple-output system, the existence of uncertainty of model parameters, the external disturbances [3]. In recent years, the Sliding Mode Control (SMC) method has been widely used for robust control of nonlinear systems. Sliding mode control, based on the theory of variable structure systems, has attracted a lot of research on control systems for the last two decades. It achieves robust control by adding a discontinuous control signal across the sliding surface, satisfying the sliding condition, [4-6]. Nevertheless, this type of control has an essential disadvantage, which is the chattering phenomenon caused by the discontinuous control action, [7, 8].

In the literature, several methods have been developed by researchers to reduce this phenomenon [9, 10]. In this work, a hybridization between the Adaptive Fuzzy Logic Control and the Sliding Mode will be applied to the power control of the DFIG. Integrated in a wind system in order to increase the performance of the sliding mode control, namely; minimizing the effect of the chattering phenomenon and improving the robustness of the system.

This paper is devised in 5 sections as follows: in Section 2 the system modeling is briefly reviewed. The control of active and reactive powers of the DFIG using two different nonlinear controllers; sliding mode and Adaptive Fuzzy Sliding Mode is presented in Section 3. In Section 4, the two controllers are compared in terms of power reference tracking. Finally, in Section 5 the main conclusions of the work are drawn.

\section{Wind turbine conversion system}

A wind turbine conversion system is a system that converts the wind turbines mechanical energy obtained from 
wind into electrical energy through a generator calibrated according to nominal turbine speed, number of generator pole-pairs and network frequency [11]. Fig. 1 shows the synoptic scheme of the studied system.

The main parts of this scheme are:

- the wind turbine,

- the gearbox and generator,

- the rotor-side converter (RSC)

- and the grid-side converter (GSC) connected backto-back by a dc-link capacitor.

\subsection{Turbine modeling}

The theoretical power produced by the wind is given by [12]:

$P_{t u r}=C_{p} \frac{\rho \times S \times V_{v}^{3}}{2}$,

where $C_{p}$ represents the wind turbine power conversion efficiency. It is a function of the tip speed ratio $\lambda$ and the blade pitch angle $\beta$ in a pitch-controlled wind turbine.

$\lambda$ is defined as the ratio of the tip speed of the turbine blades to wind speed [12]:

$\lambda=\frac{R \times \Omega_{t}}{V_{v}}$,

where $R$ is blade radius. $\Omega$ is angular speed of the turbine.

$C_{p}$ can be described as [13]:

$C_{p}=(0.5-0.0167 \times(\beta-2)) \times \sin \left[\frac{\pi(\lambda+0.1)}{18.5-0.3 \times(\beta-2)}\right]$

$-0.0018 \times(\lambda-3)(\beta-2)$.

The aerodynamic torque expression is given by [11]:

$T_{t}=\frac{P_{t}}{\Omega_{t}}=C_{p} \times \frac{\rho \times S \times V_{v}^{3}}{2 \times \Omega_{t}}$.

The gearbox is installed between the turbine and generator to adapt the speed of the turbine to that of the generator [11]:

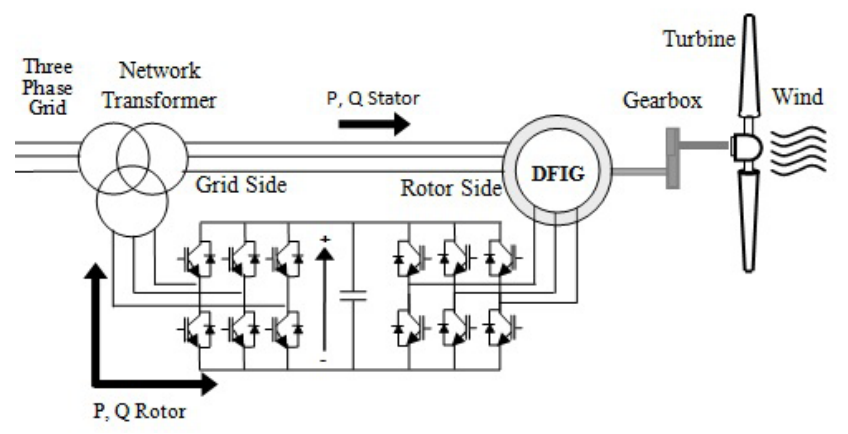

Fig. 1 Wind energy conversion chain.
$\Omega_{g}=G \times \Omega_{t}$.

The mechanical equations of the system can be characterized by [11]:

$T_{m e c}-T_{e m}=\left(\frac{J_{t u r}}{G^{2}}+J_{g e n}\right) \frac{d \Omega_{g}}{d t}+f_{v} \times \Omega_{g}$.

\subsection{Mathematical modeling of DFIG}

In the literature, the Park model of the DFIG is largely used [14]. The equations of voltages for the DFIG stator and rotor in the Park reference frame are given as follows [15]:

$\left\{\begin{array}{l}V_{s d}=R_{s} i_{s d}+\frac{d}{d t} \phi_{s d}-\omega_{s} \phi_{s q} \\ V_{s q}=R_{s} i_{s q}+\frac{d}{d t} \phi_{s q}+\omega_{s} \phi_{s d}\end{array}\right.$,

$\left\{\begin{array}{l}V_{r d}=R_{r} i_{r d}+\frac{d}{d t} \phi_{r d}-\omega_{r} \phi_{r q} \\ V_{r q}=R_{r} i_{r q}+\frac{d}{d t} \phi_{r q}+\omega_{r} \phi_{r d}\end{array}\right.$,

where the rotor frequency $\omega_{r}$ is given by:

$\omega_{r}=\omega_{s}-\omega$.

The flux equations of the DFIG are:

$\left\{\begin{array}{l}\phi_{s d}=L_{s} i_{s d}+M i_{r d} \\ \phi_{s q}=L_{s} i_{s q}+M i_{r q}\end{array}\right.$

$\left\{\begin{array}{l}\phi_{r d}=L_{r} i_{r d}+M i_{s d} \\ \phi_{r q}=L_{r} i_{r q}+M i_{s q}\end{array}\right.$

The electrical model of the DFIG is completed by the following mechanical equation (Eq. (12)):

$T_{e m}=T_{r}+f \times \Omega+J \times \frac{d \Omega}{d t}$.

Here, the electromagnetic torque $T_{e m}$ can be written as follows [16]:

$T_{e m}=\frac{3}{2} p \frac{M}{L_{s}}\left(\phi_{s q} i_{r d}-\phi_{s d} i_{r q}\right)$

The active and reactive stator and rotor powers are given by [17]:

$\left\{\begin{array}{l}P_{s}=\frac{3}{2}\left(v_{s d} i_{s d}+v_{s q} i_{s q}\right) \\ Q_{s}=\frac{3}{2}\left(v_{s q} i_{s d}-v_{s d} i_{s q}\right)\end{array}\right.$,
$\left\{\begin{array}{l}P_{r}=\frac{3}{2}\left(v_{r d} i_{r d}+v_{r q} i_{r q}\right) \\ Q_{r}=\frac{3}{2}\left(v_{r q} i_{r d}-v_{r d} i_{r q}\right)\end{array}\right.$. 


\section{Design of the Sliding Mode Control}

The basic idea of Sliding-Regime Control is first to draw the states of the system to a suitably selected region, then to design a law of command that will always maintain the system in this region [18]. As a result the Sliding Mode Control is based on the following steps [19]:

1. selection of the switching hyperplane to impose the desired dynamics for the controlled system and

2. design of the discontinuous control such that the system enters the sliding mode regime and remains there.

The model of this system is demonstrated for a following nonlinear system [20]:

$\dot{x}=f(x, t)+B(x, t) \times u(x, t)$,

where $x \in \mathfrak{R}^{n}$ is the state vector, $f(x, t) \in \mathfrak{R}^{n}$, $B(x, t) \in \mathfrak{R}^{n \times m}, u \in \mathfrak{R}^{m}$ is the control vector.

In the proposed SMC control scheme, the following sliding surface is used [21]:

$$
\begin{aligned}
& S(x, t)=\left(\frac{d}{d t}+\lambda\right)^{n-1} e(t), \\
& e(x)=X_{\text {ref }}-X
\end{aligned}
$$

where

- $e(x)$ : denotes the error of the controlled greatness;

- $\lambda$ : is a positive coefficient,

- $n$ : denotes the order of the system.

- $X_{\text {ref }}$ : reference greatness.

Consider a Lyaponov function [22]:

$V=\frac{1}{2} S^{2}$.

From Lyaponov theorem we know that if $V$ is negative definite, the system trajectory will be driven and attracted toward the sliding surface and remain sliding on it until the origin is reached asymptotically [23]:

$V=\frac{1}{2} \frac{d}{d t} S^{2}=S \dot{S} \leq-\eta|\sigma|$,

where $\eta$ is a strictly positive constant.

The sliding control law $u(t)$ is defined as:

$\left\{\begin{array}{l}u=u^{e q}+u^{n} \\ u^{n}=-K_{f} \times \operatorname{sat}(S(x, t) / \zeta)\end{array}\right.$,

where $u$ is the control vector, $u^{e q}$ is the equivalent control vector, $u^{n}$ is the switching part of the control (the correction factor), $K_{f}$ is the controller gain, $u^{e q}$ can be obtained by considering the condition for the sliding regime, $S(x, t)$ and $\zeta>0$.

Fig. 2 shows the soft command at a threshold.

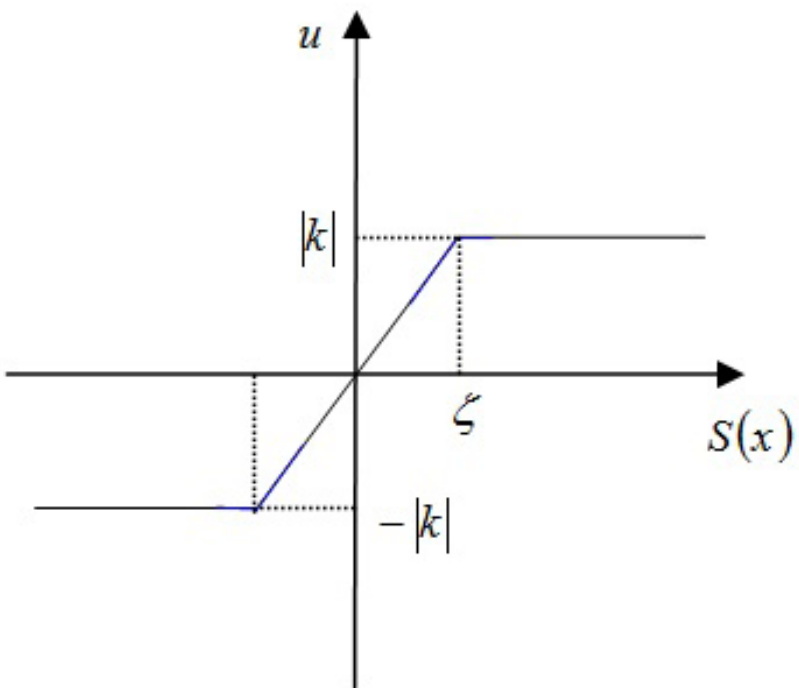

Fig. 2 Representation of the soft command at a threshold.

Concerning the DFIG control using sliding mode theory, the surfaces are chosen as functions of the error between the reference input signal and the measured signals.

\subsection{Application of Sliding Mode Control of DFIG}

In this work we will choose a reference frame linked to the stator flux and if the per phase stator resistance is neglected, which is a realist approximation for medium and high power machines used in wind energy conversion, the stator voltage vector is consequently in quadrature advance in comparison with the stator flux vector:

$V_{s d}=0, V_{s q}=V_{s} \approx \omega_{s} \times \phi_{s}$.

We obtains an uncoupled power control, where the component $i_{r q}$ of the rotor current controls the active power. The reactive power is imposed by the direct component $i_{r d}$.

$P_{s}=-V_{s} \frac{M}{L_{s}} i_{r q}$

$Q_{s}=\frac{V_{s}^{2}}{\omega_{s} L_{s}}-V_{s} \frac{M}{L_{s}} i_{r d}$

The arrangement of the equations gives the expressions of the voltages according to the rotor currents:

$\dot{i}_{r d}=-\frac{1}{\sigma T_{r}} i_{r d}+g \omega_{s} i_{r q}+\frac{1}{\sigma L_{r}} V_{r d}$,

$\dot{i}_{r q}=-\left(\frac{1}{T_{r}}+\frac{M^{2}}{L_{s} T_{s} L_{r}}\right) \times \frac{1}{\sigma} \times i_{r q}-g \omega_{s} i_{r d}+\frac{1}{\sigma L_{r}} V_{r q}$,

with

$T_{s}=\frac{L_{s}}{R_{s}}, T_{r}=\frac{L_{r}}{R_{r}}, \sigma=1-\frac{M^{2}}{L_{s} L_{r}}$. 


\subsubsection{Regulation surface of the active statoric power with SMC}

The sliding surface representing the error between the measured and reference active power, is given by this relation:

$e=P_{s}^{*}-P_{s}$.

We can write:

$\dot{S}\left(P_{s}\right)=\dot{P}_{s}^{*}-\dot{P}_{s}$.

Its derivative is

$\dot{S}\left(P_{s}\right)=\dot{P}_{s}^{*}-\dot{P}_{s}$.

Substituting the expression of $P_{s}$ Eq. (22) in Eq. (28), we obtain:

$\dot{S}\left(P_{s}\right)=\dot{P}_{s}^{*}-\left(-V_{s} \frac{M}{L_{s}} \dot{i}_{r q}\right)$.

Substituting the expression of $i_{r q}$ Eq. (25) in Eq. (29), we obtain:

$\dot{S}\left(P_{s}\right)=\dot{P}_{s}^{*}+V_{s} \frac{M}{L_{s} L_{r} \sigma}\left(V_{r q}-R_{r} \times i_{r q}\right)$.

We take:

$V_{r q}=V_{r q}^{e q}+V_{r q}^{n}$

During the sliding mode and in permanent regime, we have:

$S\left(P_{s}\right)=0 ; \dot{S}\left(P_{s}\right)=0 ; V_{r q}^{n}=0$,

where the equivalent expression is:

$V_{r q}^{e q}=R_{r} \times i_{r q}-\dot{P}_{s}^{*} \times \frac{L_{s} L_{r} \sigma}{V_{s} M}$.

Therefore, the correction factor is given by:

$V_{r q}^{n}=K_{V_{r q}} \times \operatorname{Sat}\left(S_{\left(P_{s}\right)} / \zeta\right)$

where $K_{V_{r q}}$ is the positive constant.

\subsubsection{Regulation surface of the reactive statoric power with SMC}

The sliding surface representing the error between the measured and reference reactive power, is given by this relation:

$e=Q_{s}^{*}-Q_{s}$.

We can write:

$S\left(Q_{s}\right)=e=Q_{s}^{*}-Q_{s}$.
Its derivative is

$\dot{S}\left(Q_{s}\right)=\dot{Q}_{s}^{*}-\dot{Q}_{s}$.

Substituting the expression of $Q_{s}$ Eq. (23) in Eq. (37), we obtain:

$\dot{S}\left(Q_{s}\right)=\dot{Q}_{s}^{*}-\left(\frac{V_{s}^{2}}{\omega_{s} L_{s}}-V_{s} \frac{M}{L_{s}} i_{r d}\right)$.

Substituting the expression of $\dot{i}_{r d}$ Eq. (24) in Eq. (38), we obtain:

$\dot{S}\left(Q_{s}\right)=\dot{Q}_{s}^{*}+V_{s} \frac{M}{L_{s} L_{r} \sigma}\left(V_{r d}-R_{r} \times i_{r d}\right)$.

We take:

$V_{r d}=V_{r d}^{e q}+V_{r d}^{n}$

During the sliding mode and in permanent regime, we have:

$S\left(Q_{s}\right)=0 ; \dot{S}\left(Q_{s}\right)=0 ; V_{r d}^{n}=0$,

where the equivalent control is:

$V_{r d}^{e q}=R_{r} \times i_{r d}-\dot{Q}_{s}^{*} \times \frac{L_{s} L_{r} \sigma}{V_{s} M}$.

Therefore, the correction factor is given by:

$V_{r d}^{n}=K_{V_{r d}} \times \operatorname{Sat}\left(S_{\left(Q_{s}\right)} / \zeta\right)$,

where $K_{V_{r d}}$ is the positive constant.

Fig. 3 shows block diagram of the power control of the DFIG with SMC.

\subsection{Control strategy by Adaptive Fuzzy Sliding Mode}

In order to improve the performance of this control strategy especially elimination of phenomenon of chattering, several methods have been proposed. In our paper, we propose the hybrid approach of Adaptive Fuzzy Logic and Sliding Mode Control (AFSMC).

Adaptive Fuzzy Sliding Mode Control meets the objectives described in the introduction by its robustness to the modeling uncertainties of the generator and the wind turbine. It therefore increases reliability, improves energy efficiency and, with chattering elimination, it limits the mechanical stress on the entire transmission of the wind turbine $[22,24]$.

It has the same control law as the SMC set to apart from the parameters $K$ and $\xi$ the component $V^{n}$ that will be adapted by a system to a fuzzy inference. 


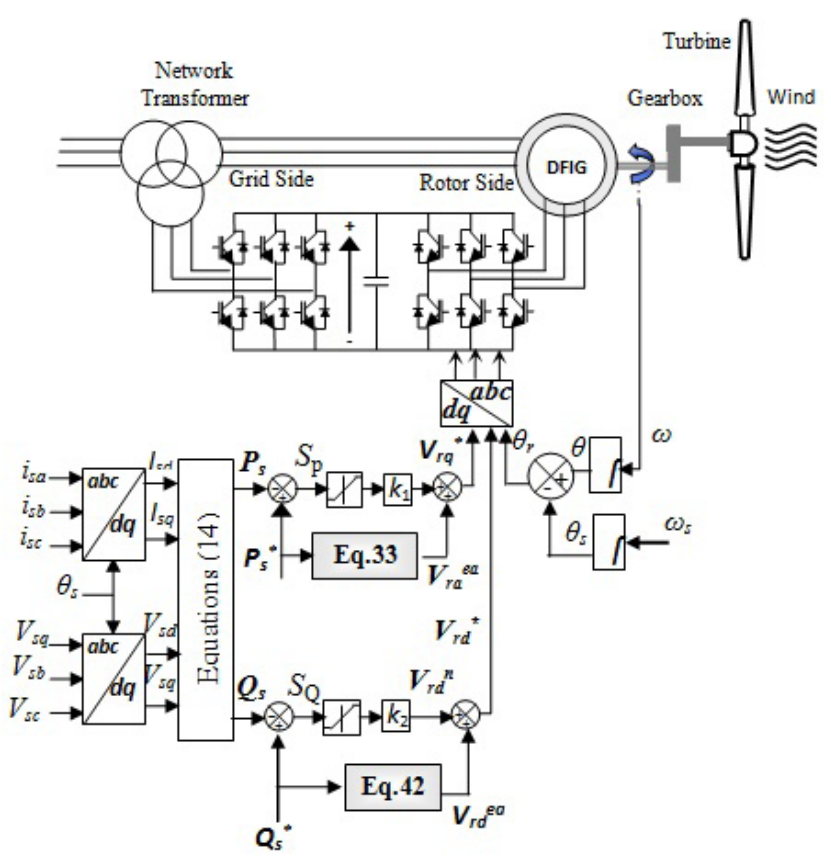

Fig. 3 Block diagram of the power control of the DFIG with SMC.

The terms $k$ and $\xi$ are therefore adapted by a fuzzy adapter having two inputs $(\varepsilon)$ and $(d \varepsilon)$ of three membership functions and an " $\alpha$ " output of nine membership functions which are represented in Figs. 4 and 5 respectively.

The linguistic terms used here are represented in Table 1.

Therefore, the discontinuous control law of Eq. (34) becomes:

$V_{r q_{n}}^{f l}=k_{V_{r q}}^{f l} \operatorname{sat}\left(s\left(P_{s}\right) / \xi^{f l}\right)$,

with

$\left\{\begin{array}{l}k_{V_{r q}}^{f l}=\alpha k_{V_{r q}} \\ \xi^{f l}=\alpha \xi\end{array}\right.$.

For the control law of Eq. (44), we will see in a transient state a series of values of $k_{V_{r q}}^{f l}$ and $\xi^{f l}$, which gives an infinite number of $s a t\left(s\left(P_{s}\right) / \xi^{f l}\right)$ functions. In steady state, the magnitude $\alpha$ takes the value "1".

The discontinuous control law of Eq. (43) becomes:

$V_{r d_{n}}^{f l}=k_{r_{r d}}^{f l} s a t\left(s\left(Q_{s}\right) / \xi^{f l}\right)$

with

$\left\{\begin{array}{l}k_{V_{r d}}^{f l}=\alpha k_{V_{r d}} \\ \xi^{f l}=\alpha \xi\end{array}\right.$.

The rules governing the gain adaptation law and the parameter are presented in Table 2.

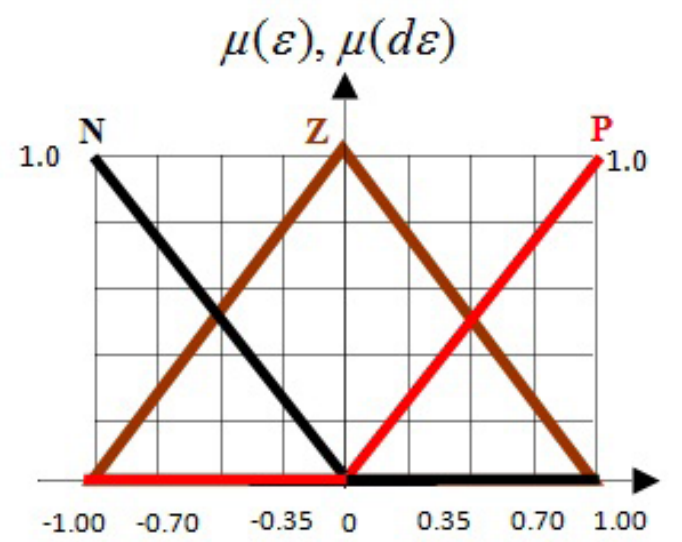

Fig. 4 The inputs membership functions of the AFSMC controller.

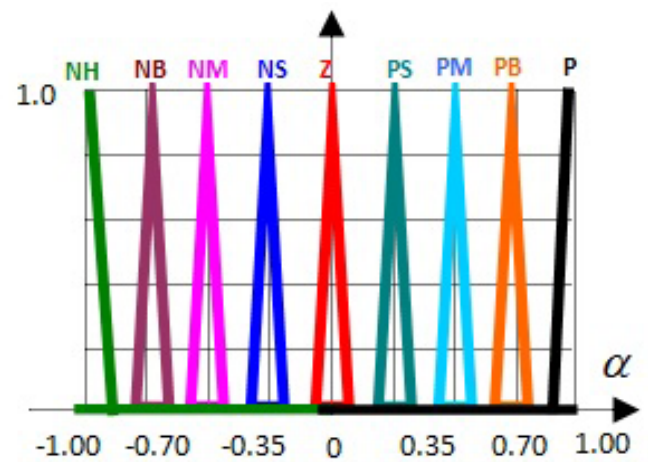

Fig. 5 The output membership functions of the AFSMC controller.

Table 1 Linguistic terms

\begin{tabular}{lccc}
\hline N & Negative & P & Positive \\
\hline Z & Zero & NB & Negative Big \\
NS & Negative Small & NM & Negative Medium \\
PS & Positive Small & PM & Positive Medium \\
& \multicolumn{3}{c}{ PB Positive Big } \\
\hline
\end{tabular}

Table 2 The rules governing the Gain Adaptation Law and the parameter

\begin{tabular}{llllllll}
\hline$R_{1}:$ if & $S$ & is $\mathrm{P}$ & and $\dot{S}$ is $\mathrm{P}$, & then & $\alpha$ & is & $\mathrm{N}$. \\
\hline$R_{2}:$ if & $S$ & is $\mathrm{P}$ & and $\dot{S}$ is $\mathrm{Z}$, & then & $\alpha$ & is & $\mathrm{NB}$. \\
$R_{3}:$ if & $S$ & is $\mathrm{P}$ & and $\dot{S}$ is $\mathrm{N}$, & then & $\alpha$ & is & $\mathrm{NM}$. \\
$R_{4}:$ if & $S$ & is $\mathrm{Z}$ & and $\dot{S}$ is $\mathrm{P}$, & then & $\alpha$ & is & $\mathrm{NS}$. \\
$R_{5}:$ if & $S$ & is $\mathrm{Z}$ & and $\dot{S}$ is $\mathrm{Z}$, & then & $\alpha$ & is & $\mathrm{ZE}$. \\
$R_{6}:$ if & $S$ & is $\mathrm{Z}$ & and $\dot{S}$ is $\mathrm{N}$, & then & $\alpha$ & is & $\mathrm{PS}$. \\
$R_{7}:$ if & $S$ & is $\mathrm{N}$ & and $\dot{S}$ is $\mathrm{P}$, & then & $\alpha$ & is & $\mathrm{PM}$. \\
$R_{8}:$ if & $S$ & is $\mathrm{N}$ & and $\dot{S}$ is $\mathrm{Z}$, & then & $\alpha$ & is & $\mathrm{PB}$. \\
$R_{9}:$ if & $S$ & is $\mathrm{N}$ & and $\dot{S}$ is $\mathrm{N}$, & then & $\alpha$ & is & $\mathrm{P}$. \\
\hline
\end{tabular}


Fig. 6 shows block diagram of the power control of the DFIG with AFSMC.

\section{Results and analysis}

To test the performance of the proposed approach in wind turbine active/reactive power regulation; a comparative study is conducted under variable wind speed. Simulation model is constructed in Matlab/Simulink. The parameters utilized are listed in Appendix.

This test is to achieve active and reactive power steps while the machine is driven at variable speed.

The main purpose of this test is the study and comparison of the behavior of the two types of Sliding Mode Controllers (SMC and AFSMC) used in this work with respect to the monitoring of the proposed regulation instructions and the effect of Chattering phenomenon on the quality of the current leaving the stator windings and the rotor of the DFIG.

The simulation results obtained are shown in Figs. 7 and 8. As shown in these figures, it is noted for the two types of controllers used that the active and reactive powers measured perfectly follow their references and with almost perfect decoupling between the two axes $d$ and $q$. We can also notice that the electromagnetic torque (Fig. 9) depends directly on the active power. This is translated by its shape identical to that of the active power. In this case, we can conclude that the active power is a consequence of the electromagnetic torque; while the reactive power is a consequence of the excitation of the rotor circuit.

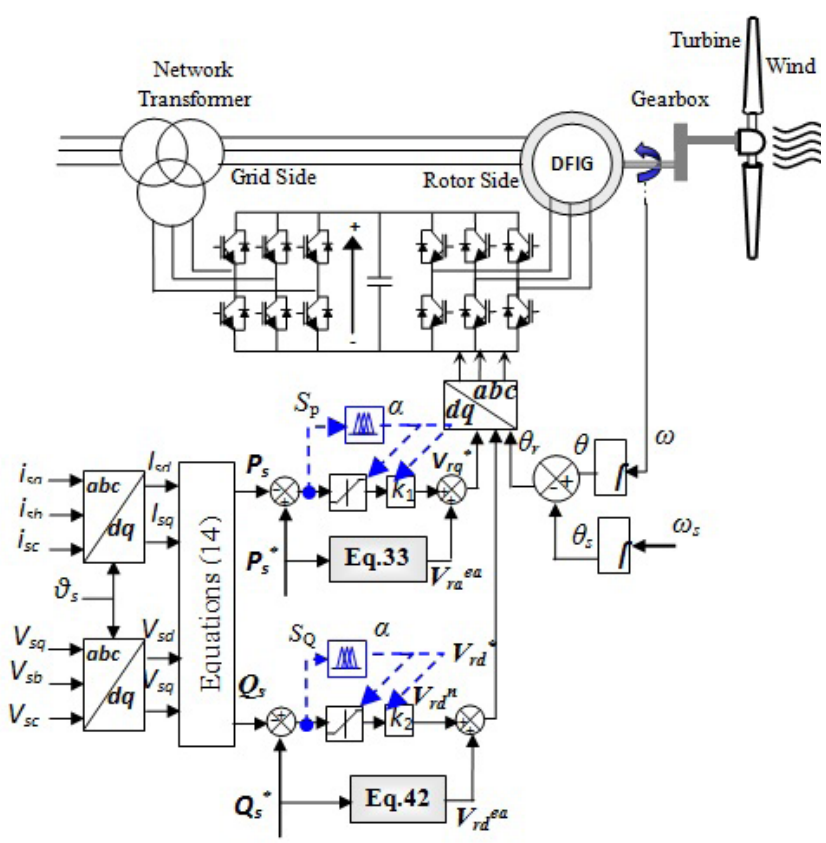

Fig. 6 Block diagram of the power control of the DFIG with AFSMC

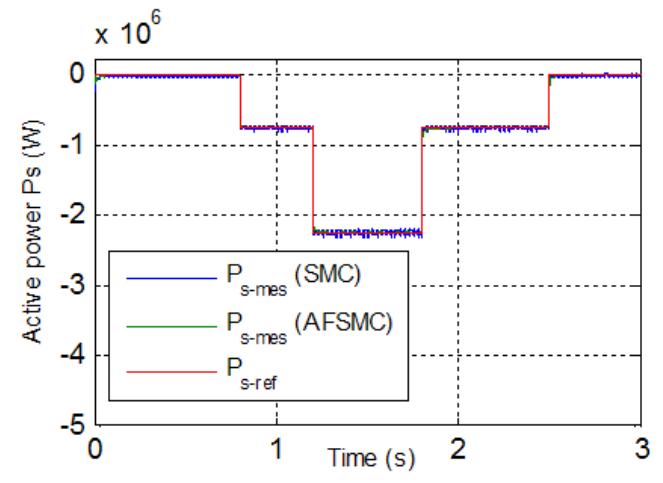

Fig. 7 Active power

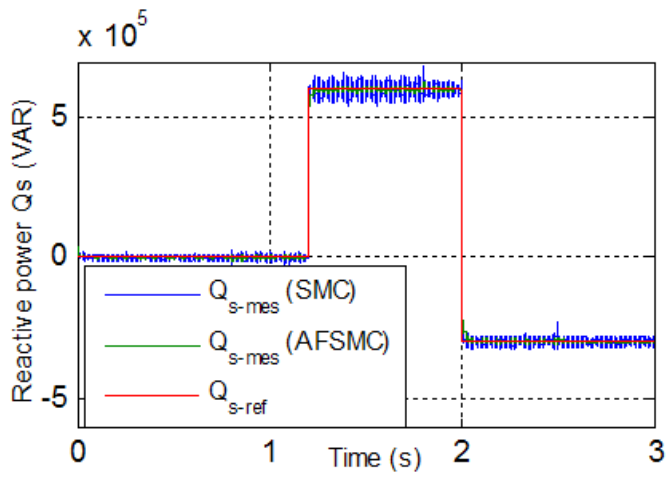

Fig. 8 Reactive power

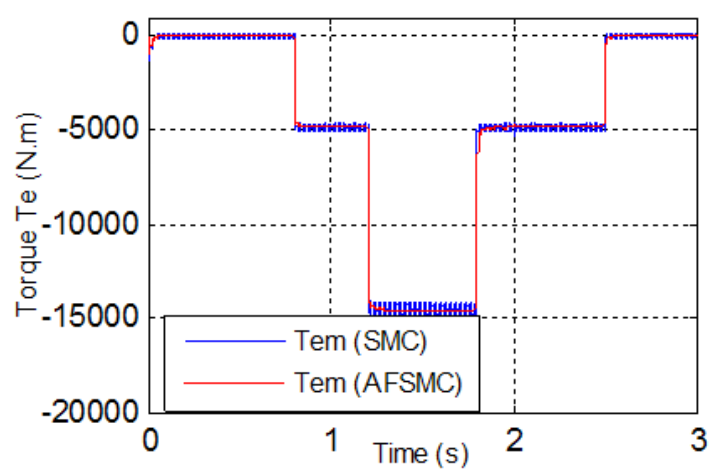

Fig. 9 Electromagnetic torque

The results obtained from Figs. 10, 11, 12 and 13 show that for the proposed controller (AFSMC), the phase stator currents have almost sinusoidal shapes, which means that a good quality energy is supplied to the network. These results allow us to conclude that the adopted controller (AFSMC) is the most efficient vis-à-vis the reduction of the chattering phenomenon compared to the SMC controller.

\section{Conclusion}

In this work, we have developed hybrid Adaptive Fuzzy Sliding Mode Control of active and reactive powers in a DFIG and performance evaluations. After a description 


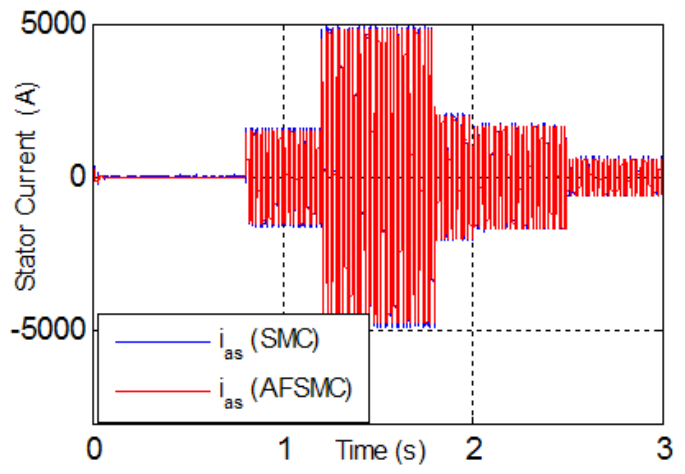

Fig. 10 Stator current

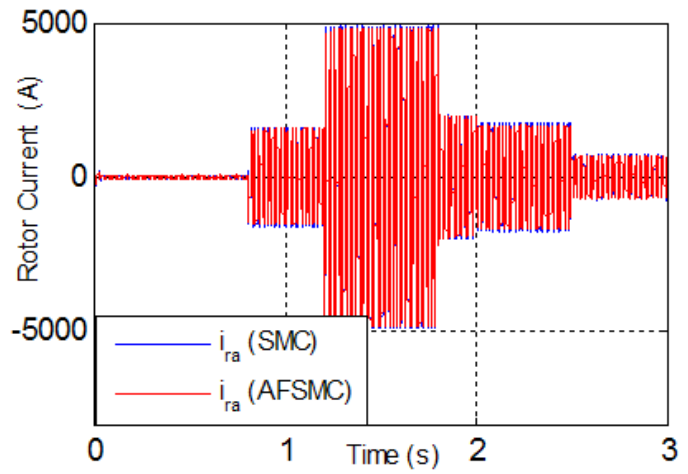

Fig. 12 Rotor current

of Doubly Fed Induction Generator with variable wind speed and fixed frequency of the grid, we have established a two-phase power mathematical model of the DFIG. In order to control the active and reactive powers exchanged between the DFIG and the grid, a hybrid Adaptive Fuzzy Sliding Mode approach using vector

\section{References}

[1] Zhang, L., Jin, X., Zhan, L. "A Novel LVRT Control Strategy of DFIG based Rotor Active Crowbar", In: 2011 Asia-Pacific Power and Energy Engineering Conference, Wuhan, China, 2011, pp. 1-6. https://doi.org/10.1109/APPEEC.2011.5749053

[2] Belmokhtar, K., Doumbia, M. L., Agbossou, K. "New sensorless fuzzy logic control strategy of wind energy conversion systems", In: International Symposium on Power Electronics, Electrical Drives, Automation and Motion, Sorrento, Italy, 2012, pp. 1-6. https://doi.org/10.1109/SPEEDAM.2012.6264585

[3] Fu, H. L., Thien, H. T. "Modeling a Wind Turbine System Using DFIG and Realization of Current Control on the Model with Fuzzy Logic Controller", In: International Conference on Advanced Engineering Theory and Applications 2013 (AETA 2013), Ho Chi Minh City, Vietnam, 2013, pp. 85-92. https://doi.org/10.1007/978-3-642-41968-3_10

[4] Saad, N. H., Sattar, A. A., Mansour, A. E. A. M. "Low voltage ride through of doubly-fed induction generator connected to the grid using sliding mode control strategy", Renewable Energy, 80, pp. 583-594, 2015.

https://doi.org/10.1016/j.renene.2015.02.054

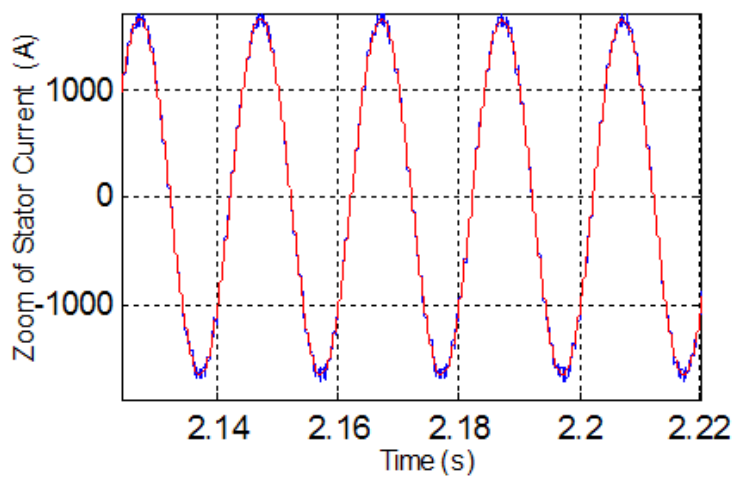

Fig. 11 Zoom of stator current

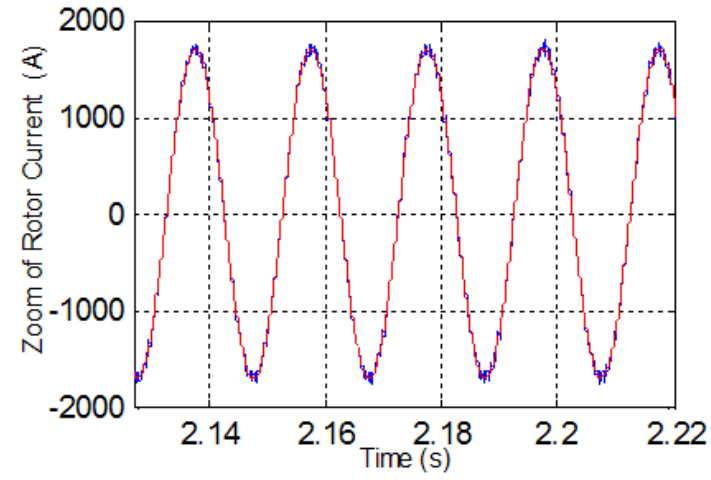

Fig. 13 Zoom of rotor current

control strategy has been presented. Responses of our system with this type of controller have shown that the last gives very interesting performances toward reference tracking and avoid the chattering phenomenon. The main parameters of the wind turbine are given in Table 3 and the main 4 parameters of the DFIG are given in Table 4 .

[5] Ponce, P., Ponce, H., Molina, A. "Doubly fed induction generator (DFIG) wind turbine controlled by artificial organic networks", Soft Computing, 22(9), pp. 2867-2879, 2018. https://doi.org/10.1007/s00500-017-2537-3

[6] Barambones, O., Alkorta, P., Gonzalez de Durana, J. M. "A realtime estimation and control scheme for induction motors based on sliding mode theory", Journal of the Franklin Institute, 351(8), pp. 4251-4270, 2014.

https://doi.org/10.1016/j.jfranklin.2014.04.020

[7] Boukezzar, B., M'Saad, M. "Robust sliding mode control of a DFIG variable speed wind turbine for power production optimization", In: 2008 16th Mediterranean Conference on Control and Automation, Ajaccio, France, 2008, pp. 795-800. https://doi.org/10.1109/MED.2008.4602145

[8] Sharma, S., Mishra, Dr. J. P., Datta, S. "Sliding mode power control of a DFIG based variable speed wind energy conversion system", In: 2015 Annual IEEE India Conference (INDICON), New Delhi, India, 2015, pp. 1-6.

https://doi.org/10.1109/INDICON.2015.7443335 
[9] Xiong, L., Li, P., Li, H., Wang, J. "Sliding Mode Control of DFIG Wind Turbines with a Fast Exponential Reaching Law", Energies, 10(11), Article Number: 1788, 2017. https://doi.org/10.3390/en10111788

[10] Habbab, M., Hazzab, A., Sicard, P. "Real Time Implementation of Fuzzy Adaptive PI-sliding Mode Controller for Induction Machine Control", International Journal of Electrical and Computer Engineering (IJECE), 8(5), pp. 2883-2893, 2018. http://doi.org/10.11591/ijece.v8i5.pp2883-2893

[11] Bedoud, K., Mahieddine, A., Bahi, T., Lakel, R., Grid, A. "Robust Control of Doubly Fed Induction Generator for Wind Turbine Under Sub-synchronous Operation Mode", Energy Procedia, 74, pp. 886-899, 2015.

https://doi.org/10.1016/j.egypro.2015.07.824

[12] Barambones, O., Gonzalez de Durana, J. M., Kremers, E. "Adaptive robust control to maximizing the power generation of a variable speed wind turbine", In: 2013 International Conference on Renewable Energy Research and Applications (ICRERA), Madrid, Spain, 2013, pp. 167-172. https://doi.org/10.1109/ICRERA.2013.6749745

[13] Abdeddaim, S., Betka, A. "Optimal tracking and robust power control of the DFIG wind turbine", International Journal of Electrical Power \& Energy Systems, 49, pp. 234-242, 2013. https://doi.org/10.1016/j.ijepes.2012.12.014

[14] Kahla, S., Soufi, Y., Sedraoui, M., Bechouat, M. "On-Off control based particle swarm optimization for maximum power point tracking of wind turbine equipped by DFIG connected to the grid with energy storage", International Journal of Hydrogen Energy, 40(39), pp. 13749-13758, 2015.

https://doi.org/10.1016/j.ijhydene.2015.05.007

[15] Zaimeddine, L. R., Undeland, T. "Control of a grid-connected double-fed induction generator wind turbine", In: 2011 IEEE Trondheim PowerTech, Trondheim, Norway, 2011, pp. 1-7. https://doi.org/10.1109/PTC.2011.6019462

[16] Bakouri, A., Abbou, A., Mahmoudi, H., Elyaalaoui, K. "Direct torque control of a doubly fed induction generator of wind turbine for maximum power extraction", In: 2014 International Renewable and Sustainable Energy Conference (IRSEC), Ouarzazate, Morocco, 2014, pp. 334-339. https://doi.org/10.1109/IRSEC.2014.7059799

\section{Appendix}

Table 3 Wind turbine parameters

\begin{tabular}{lc}
\hline Number of blades & 3 \\
\hline Blade radius, $R$ & $35.25 \mathrm{~m}$ \\
Gearbox ratio, $G$ & 90 \\
Moment of inertia, $J$ & $1000 \mathrm{~kg} \mathrm{~m}^{2}$ \\
Viscous friction coefficient, $f$ & $0.0024 \mathrm{~N} \mathrm{~m} \mathrm{~s}^{-1}$ \\
Cut-in wind speed & $4 \mathrm{~m} / \mathrm{s}$ \\
Cut-out wind speed & $25 \mathrm{~m} / \mathrm{s}$ \\
\hline
\end{tabular}

[17] Arnalte, S., Burgos, J. C., Rodríguez-Amenedo, J. L. "Direct Torque Control of a Doubly-Fed Induction Generator for Variable Speed Wind Turbines", Electric Power Components and Systems, 30(2), pp. 199-216, 2002.

https://doi.org/10.1080/153250002753427851

[18] Mechter, A., Kemih, K., Ghanes, M. "Sliding Mode Control of a Wind Turbine with Exponential Reaching Law", Acta Polytechnica Hungarica, 12(3), pp. 167-183, 2015. https://doi.org/10.12700/APH.12.3.2015.3.10

[19] Guldemir, H. "Study of Sliding Mode Control of DC-DC Buck Converter", Energy and Power Engineering, 3(4), pp. 401-406, 2011. https://doi.org/10.4236/epe.2011.34051

[20] Rahali, H., Zeghlache, S., Benalia, L., Layadi, N. "Sliding mode control based on backstepping approach for a double star induction motor (DSIM)", Advances in Modelling and Analysis C, 73(4), pp. $150-157,2018$. https://doi.org/10.18280/ama_c.730404

[21] Lei, Y., Mullane, A., Lightbody, G., Yacamini, R. "Modeling of the wind turbine with a doubly fed induction generator for grid integration studies", IEEE Transactions on Energy Conversion, 21(1), pp. 257-264, 2006. https://doi.org/10.1109/TEC.2005.847958

[22] Cruz-Zavala, E., Moreno, J. A., Fridman, L. "Fast second-order Sliding Mode Control design based on Lyapunov function", In: 52nd IEEE Conference on Decision and Control, Florence, Italy, 2013, pp. 2858-2863. https://doi.org/10.1109/CDC.2013.6760317

[23] Mohanty, K. B. "Sensorless sliding mode control of induction motor drives", In: TENCON 2008 - 2008 IEEE Region 10 Conference, Hyderabad, India, 2008, pp. 1-6. https://doi.org/10.1109/TENCON.2008.4766709

[24] Benmeziane, M., Zebirate, S., Chaker, A., Boudjema, Z. "Fuzzy sliding mode control of doubly-fed induction generator driven by wind turbine", International Journal of Power Electronics and Drive System (IJPEDS), 10(3), pp. 1592-1602, 2019. https://doi.org/10.11591/ijpeds.v10.i3.pp1592-1602

\begin{tabular}{lc}
\multicolumn{2}{c}{ Table 4 DFIG parameters } \\
\hline Rated Power $P n$ & $1.5 \mathrm{MW}$ \\
\hline Stator Voltage $V s$ & $398 / 690 \mathrm{~V}$ \\
Stator Frequency $f$ & $50 \mathrm{~Hz}$ \\
Stator Resistance $R s$ & $0.012 \Omega$ \\
Rotor Resistance $R r$ & $0.021 \Omega$ \\
Stator inductance $L_{s}$ & $0.0137 \mathrm{H}$ \\
Rotor inductance $L_{r}$ & $0.0136 \mathrm{H}$ \\
Mutual inductance $M$ & $0.0135 \mathrm{H}$ \\
Viscous friction $f$ & $0.0024 \mathrm{Nm} / \mathrm{s}$ \\
Inertia $J$ & $1000 \mathrm{~kg} \mathrm{~m}{ }^{2}$ \\
Number of pairs of poles $P$ & 2 \\
\hline
\end{tabular}

